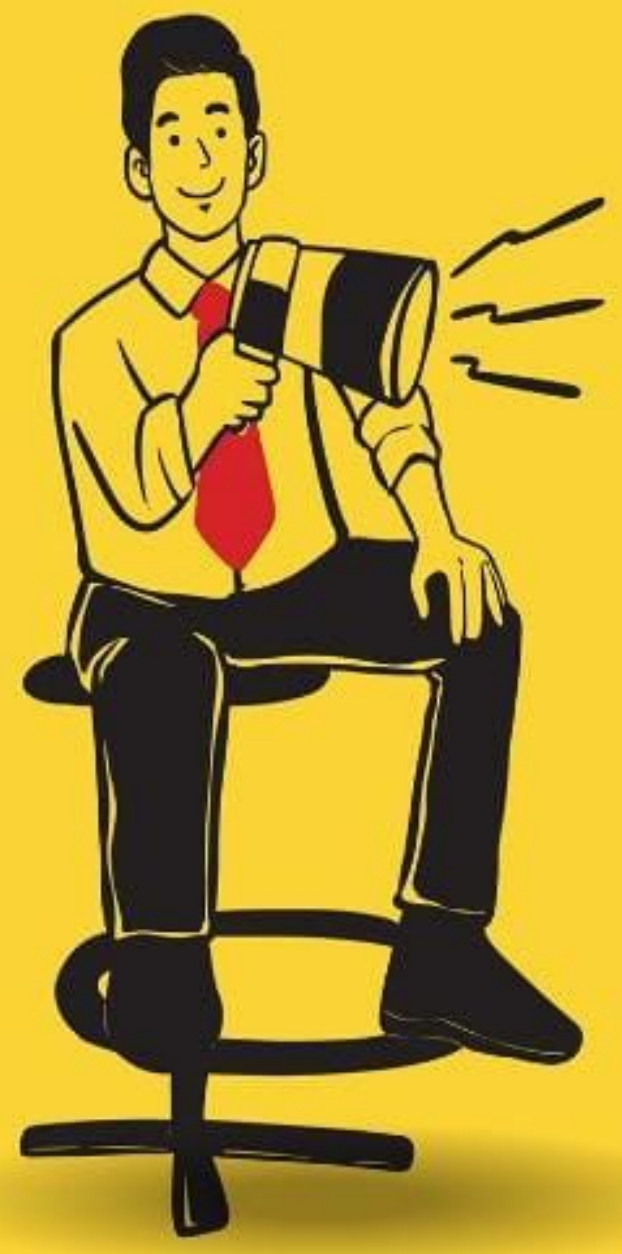

BUILDING EXCELLENT

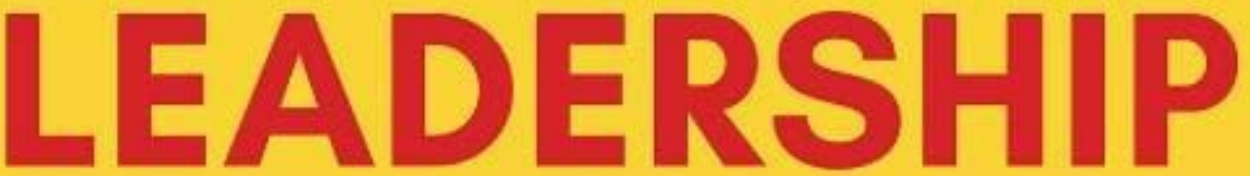

Cris Kuntadi, Antoni Ludfi Arifin, Dingot Hamonangan Ismail, Antaiwan Bowo Pranogyo 


\section{BUILDING EXCELLENT LEADERSHIP}

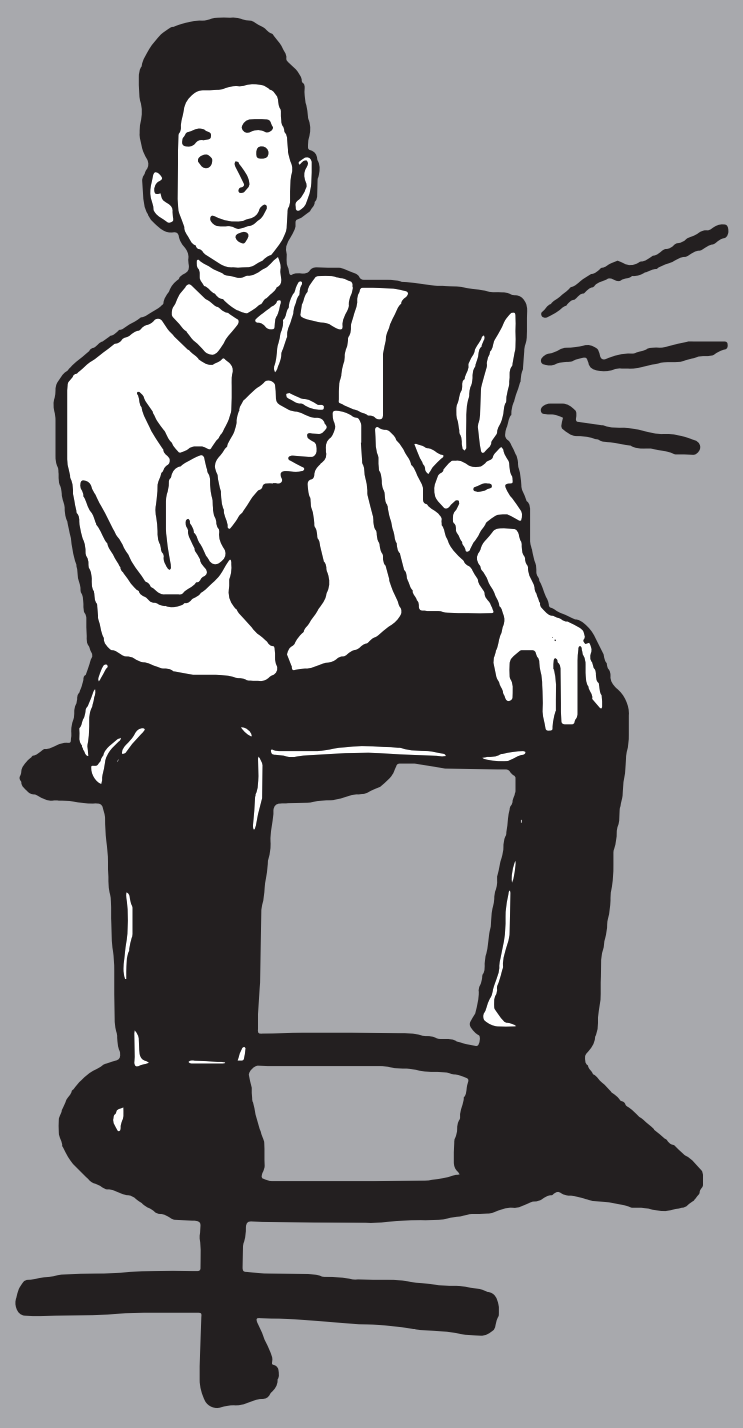

Cris Kuntadi dkk. 


\section{BUILDING EXCELLENT \\ LEADERSHIP}

Cris Kuntadi dkk.

Editor: Mia Marianne \& Antoni Ludfi Arifin

Desain Sampul : Dedy Nuryadin

Desain Halaman : Muhsinul Fajri

ISBN 978-623-373-199-7

Copyright (c) 2021

Diterbitkan pertama kali:

dandelion
PUBLISHER

Anggota IKAPI Tahun 2020

Cetakan Pertama, Januari 2022

Hakcipta dilindungi undang-undang Dilarang memperbanyak maupun mengedarkan buku dalam bentuk dan dengan cara apapun tanpa ijin tertulis dari penerbit maupun penulis. 


\section{Sanksi Pelanggaran Pasal 113 Undang-Undang Nomor 28 Tahun 2014 Tentang Hak Cipta}

1. Setiap Orang yang dengan tanpa hak melakukan pelanggaran hak ekonomi sebagaimana dimaksud dalam Pasal 9 ayat (1) huruf i untuk Penggunaan Secara Komersial dipidana dengan pidana penjara paling lama 1 (satu) tahun dan/atau pidana denda paling banyak Rp100.000.000 (seratus juta rupiah).

2. Setiap Orang yang dengan tanpa hak dan/atau tanpa izin Pencipta atau pemegang Hak Cipta melakukan pelanggaran hak ekonomi Pencipta sebagaimana dimaksud dalam Pasal 9 ayat (1) huruf c, huruf $d$, huruf $f$, dan/atau huruf $h$ untuk Penggunaan Secara Komersial dipidana dengan pidana penjara paling lama 3 (tiga) tahun dan/ atau pidana denda paling banyak Rp500.000.000,00 (lima ratus juta rupiah).

3. Setiap Orang yang dengan tanpa hak dan/atau tanpa izin Pencipta atau pemegang Hak Cipta melakukan pelanggaran hak ekonomi Pencipta sebagaimana dimaksud dalam Pasal 9 ayat (1) huruf a, huruf b, huruf e, dan/atau huruf g untuk Penggunaan Secara Komersial dipidana dengan pidana penjara paling lama 4 (empat) tahun dan/ atau pidana denda paling banyak Rp1.000.000.000,00 (satu miliar rupiah).

4. Setiap Orang yang memenuhi unsur sebagaimana dimaksud pada ayat (3) yang dilakukan dalam bentuk pembajakan, dipidana dengan pidana penjara paling lama 10 (sepuluh) tahun dan/atau pidana denda paling banyak Rp4.000.000.000,00 (empat miliar rupiah). 


\section{PENGANTAR PENULIS}

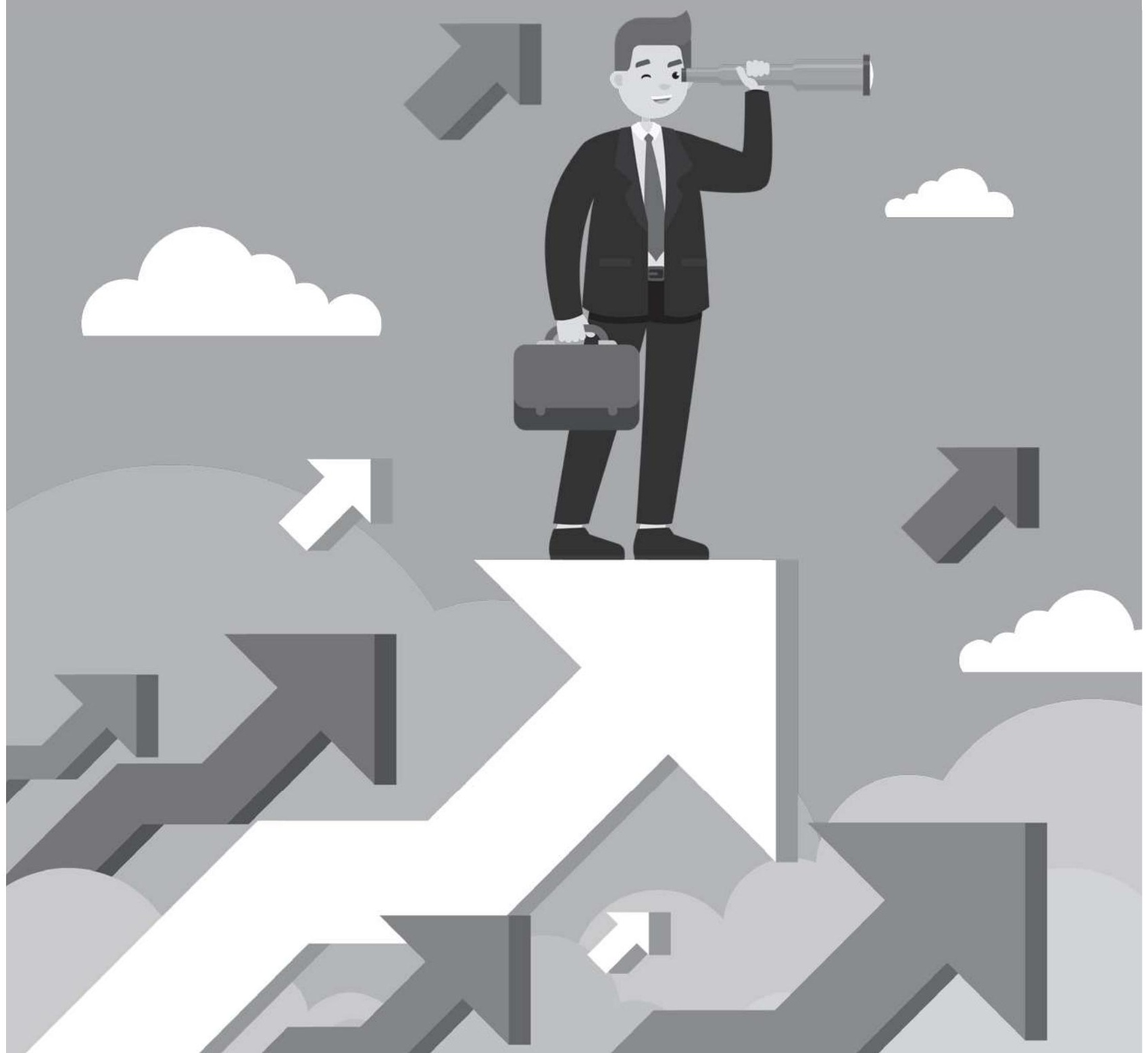


Puji syukur kita panjatkan ke hadirat Allah SWT. yang telah memberikan rahmat dan hidayahNya sehingga tiga doktor dapat menerbitkan buku perdana yang berjudul Building Excellent Leadership.

Pada 20 November 2021, kami telah melaksanakan webinar "BUILDING EXCELLENT

LEADERSHIP". Ini merupakan langkah awal kami untuk menarasikan bahasa lisan hasil webinar menjadi sebuah karya tertulis (buku). Harapan kami, residu webinar tersebut dapat melampaui ruang dan waktu: mengabadi di perpustakaanperpustakaan lembaga pendidikan dan menjadi koleksi para pembaca.

Dalam kesempatan ini, kami mengucapkan terima kasih kepada Dr. Cris Kuntadi sebagai 
anggota staf ahli Kementerian Perhubungan, Komisaris PT KAI, dan juga dosen Universitas Mercu Buana. la telah bersedia menjadi pembicara dengan memberikan ilmu dan pengalamannya agar menambah wawasan dalam bidang kepemimpinan.

Selesainya tulisan ini tidak terlepas dari bantuan berbagai pihak yang terkait secara langsung ataupun tidak langsung. Kami mengucapkan terima kasih dan mohon maaf apabila kami tidak bisa menyebutkan mereka satu per satu.

Semoga buku : BUILDING EXCELLENT LEADERSHIP ini bermanfaat bagi bangsa Indonesia agar dapat mewujudkan para pemimpin yang unggul. 


\section{Salam Cendekia}

Dr. Antoni Ludfi Arifin

Dr. Antaiwan Bowo Pranogyo

Dr. Dingot Hamonangan Ismail 


\section{DAFTAR ISI}

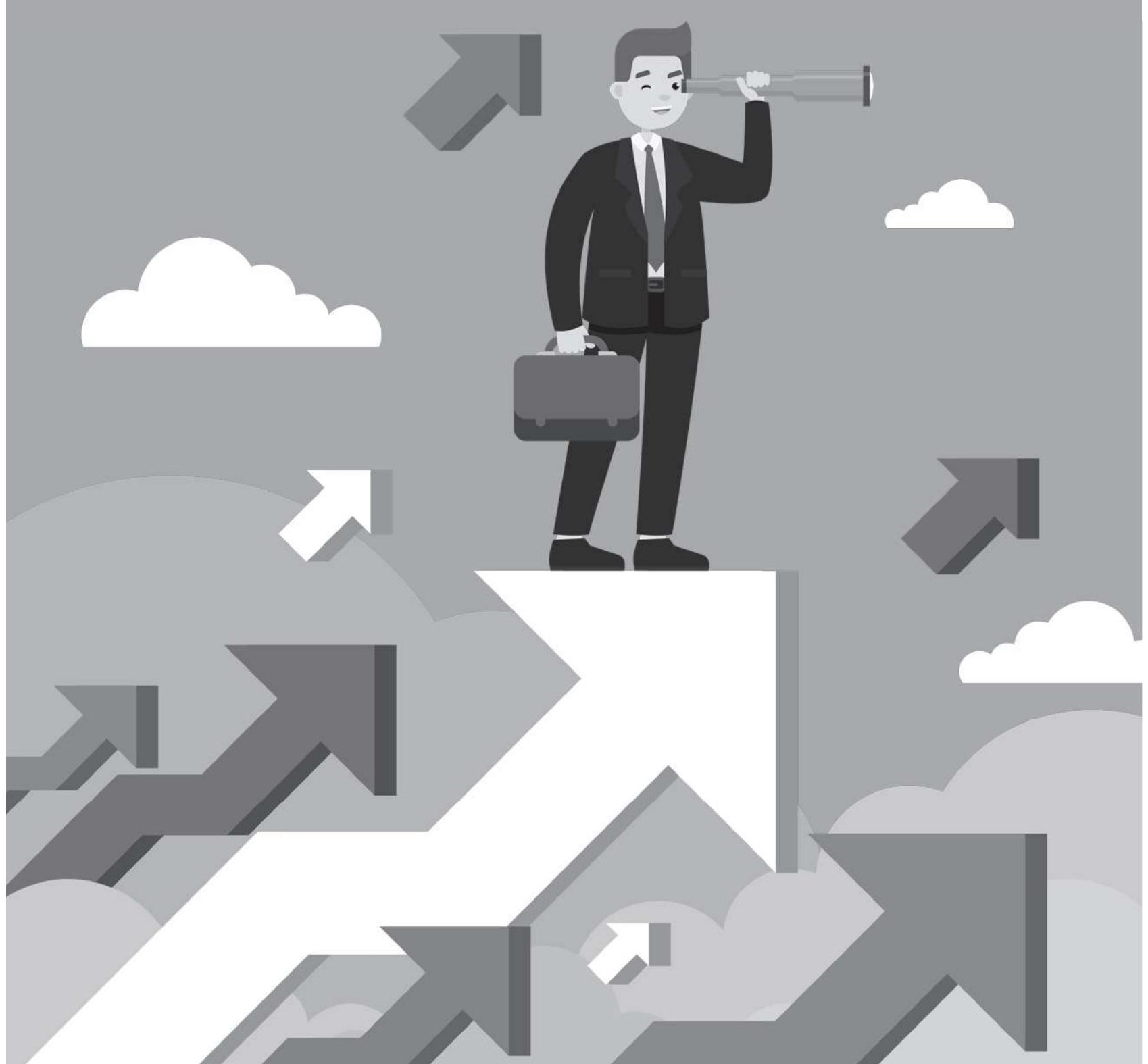


PENGANTAR PENULIS

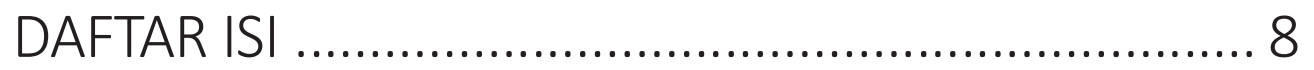

\section{BUILDING EXCELLENT LEADERSHIP}

Dr. H. Cris Kuntadi............................................... 10

\section{EXCELLENT LEADERSHIP PRESPEKTIF CENDEKIA}

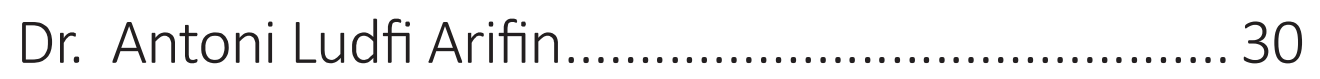

\section{EXCELLENT LEADERSHIP PRESPEKTIF HAPPINESS}

Dr. Dingot Hamonangan Ismail, M.Si ..................... 54

\section{BUDAYA KEPEMIMPINAN UNGGUL}

Dr. Antaiwan Bowo Pranogyo ................................. 84

DAFTAR PUSTAKA .............................................. 114 


\section{BUILDING EXCELLENT LEADERSHIP \\ Dr. H. Cris Kuntadi}

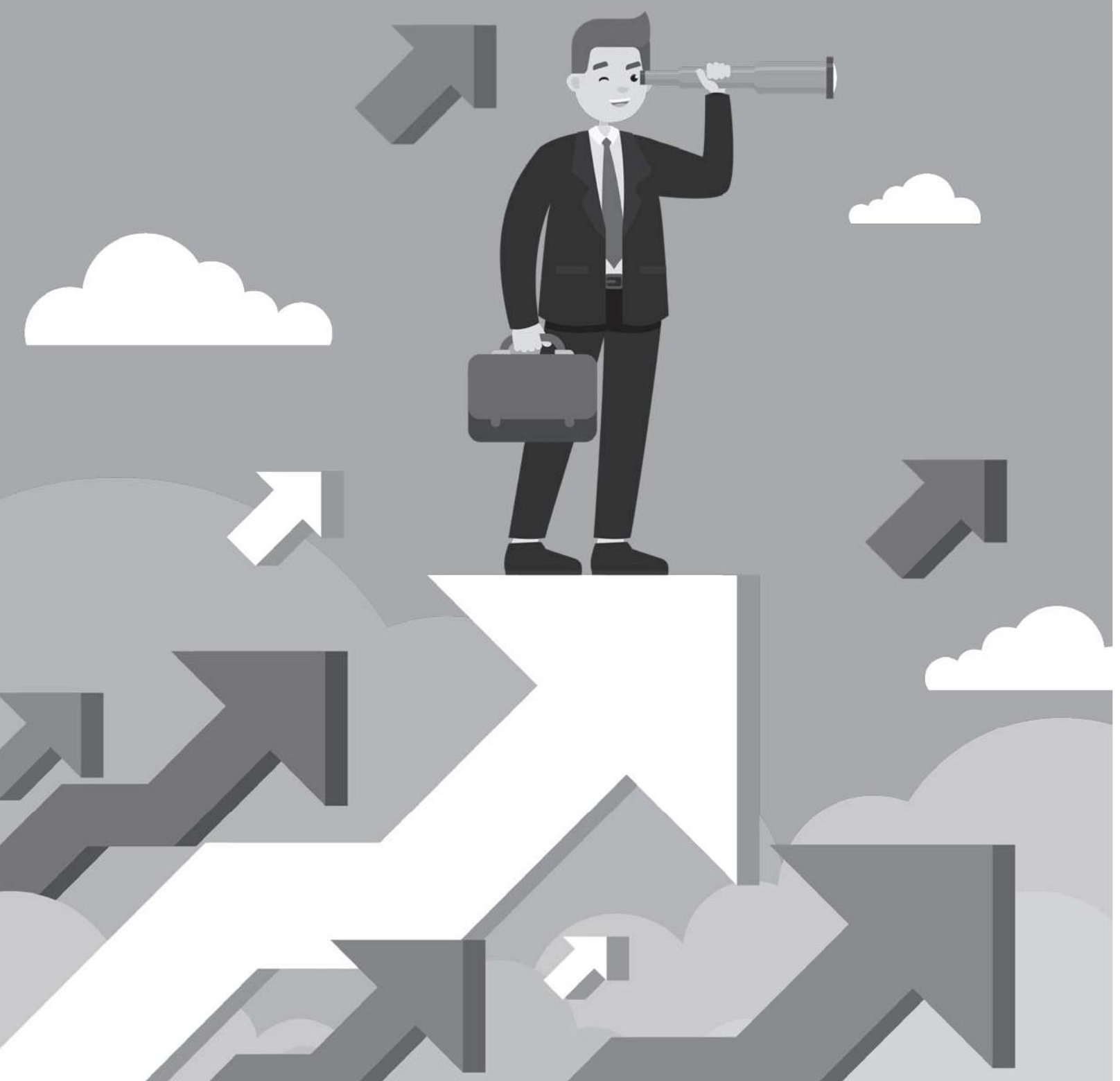




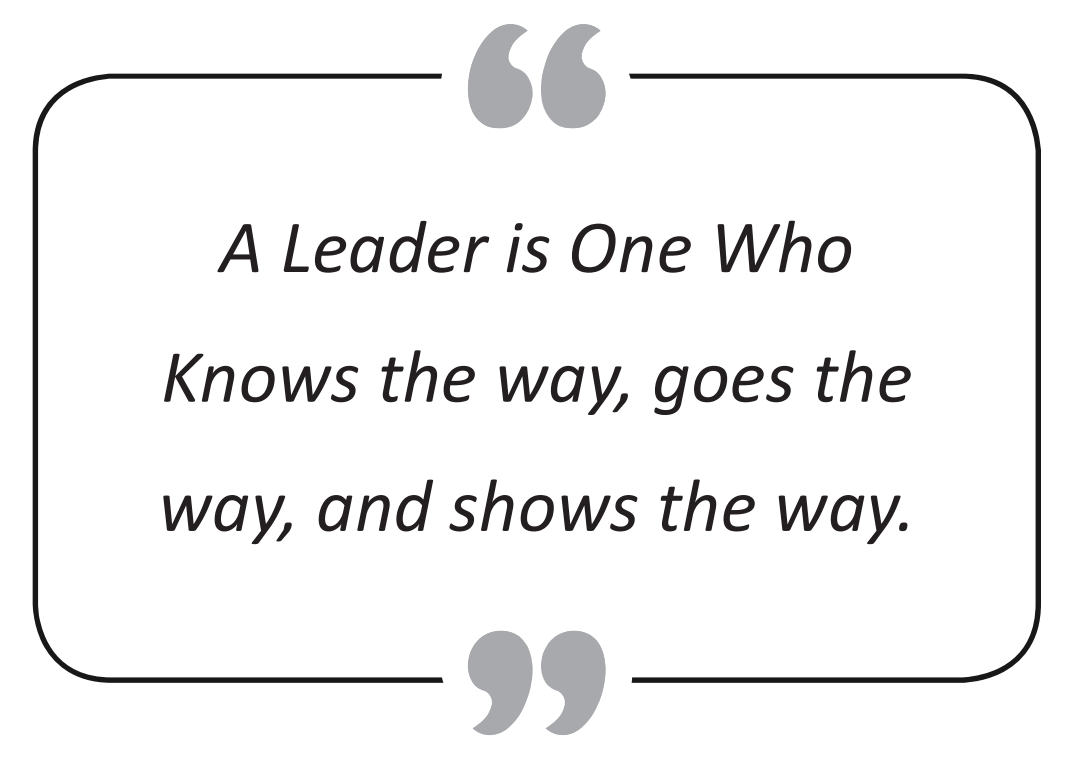

John Maxwell 


\section{PENDAHULUAN}

Pertama, saya memberikan apresiasi luar biasa untuk tiga doktor hebat yang menggagas buku ini. Buku ini, selain memperkaya perspektif kita tentang kepemimpinan, yang merupakan output dari webinar yang dapat dikomsumsi oleh generasi berikutnya, tidak hanya terbatas pada bahasa lisan hasil webinar, namun juga diawetkan ke dalam bahasa tulisan: buku.

Karena saya senang, webinar "Excellent Leadership" dapat menghasilkan output buku yang bisa dinikmati para cerdik cendekia lain untuk mengakselerasi kemajuan bangsa tercinta ini. 
Tulisan ini menyampaikan gagasan tentang excellent leadership. Kepemimpinan terbaik, sebuah tema yang sangat saya sukai.

Sebab, memang saya selalu berupaya melakukan yang terbaik dalam berkarya. Demikian juga dengan kepemimpinan. Semua orang punya potensi kepemimpinan yang hebat dalam dirinya, asalkan mau mengembangkannya dengan sungguh-sungguh. Hal ini dimulai dengan mengubah halangan mental seperti tecermin dalam pengalaman penulis berikut ini.

Suatu waktu saya diundang oleh kawan saya yang kebetulan seorang motivator terkenal dan pakar mental block. 
Saya ketika itu diminta untuk sharing knowledge (berbagi pengetahuan) dengan PT Indonesia Power, anak perusahaan PT Perusahaan Listrik Negara (PLN) yang cukup besar.

Saat itu saya diminta memberikan motivasi kepada direksi Indonesia Power dan direksi semua anak perusahaannya serta para manajer setingkat di bawah direksi yang jumlahnya sekitar 70 orang.

Saya waktu itu langsung menerima permintaan tersebut. Sebab, saya sedang mengaplikasikan keberanian dan kepedean saya dalam berbagi. Maka itu saya setuju.

Namun, menjelang hari pelaksanaan, saya kesulitan menyiapkan materi yang akan disampaikan. 
Saya gagal menyiapkan mental. Selalu muncul pertanyaan dalam batin saya, "Apakah materi yang saya berikan ini cocok atau tidak dengan keperluan mereka. Apakah akan mencerahkan para pemimpin tersebut atau tidak?"

Akhirnya saya menghubungi rekan via telepon, Pak Edi Santoso, yang menawarkan kesempatan menjadi pembicara. Saya katakan sepertinya tidak bisa mengisi acara di Indonesia Power.

Beliau bertanya, "Apakah ada acara mendadak atau ada faktor lain sehingga tidak bisa tampil?" tanya Pak Edi Santoso.

Saya jawab dengan jujur bahwa bukan itu penyebabnya. Penyebabnya, saya gagal berkalikali dalam menyiapkan materi presentasi. "Mas 